\title{
Satellite-based technique for nowcasting of thunderstorms over Indian region
}

\author{
Suman Goyal ${ }^{1, *}$, Ashish Kumar ${ }^{1}$, M Mohapatra ${ }^{1}$, L S Rathore ${ }^{1}$, \\ S K DubE ${ }^{2}$, RAhul SAXEnA ${ }^{1}$ and R K GiRi ${ }^{1}$ \\ ${ }^{1}$ India Meteorological Department, Lodi Road, New Delhi 110 003, India. \\ ${ }^{2}$ Amity University, Jaipur 303 007, Rajasthan, India. \\ *Corresponding author.e-mail: suman.imd@gmail.com
}

MS received 21 April 2016; revised 16 March 2017; accepted 17 March 2017; published online 31 August 2017

India experiences severe thunderstorms during the months, March-June. But these systems are not predicted well, mainly due to the absence of mesoscale observational network over Indian region and the expert system. As these are short lived systems, the nowcast is attempted worldwide based on satellite and radar observations. Due to inadequate radar network, satellite plays the dominant role for nowcast of these thunderstorms. In this study, a nowcast based algorithm ForTracc developed by Vila et al. (Weather Forecast 23:233-245, 2008) has been examined over the Indian region using Infrared Channel $(10.8 \mu \mathrm{m})$ of INSAT-3D for prediction of Mesoscale Convective Systems (MCS). In this technique, the current location and intensity in terms of Cloud Top Brightness Temperature (CTBT) of the MCS are extrapolated. The purpose of this study is to validate this satellite-based nowcasting technique for Convective Cloud Clusters that helps in optimum utilization of satellite data and improve the nowcasting. The model could predict reasonably the minimum CTBT of the convective cell with average absolute error (AAE) of $<7 \mathrm{~K}$ for different lead periods (30-180 min). However, it was underestimated for all the lead periods of forecasts. The AAE in the forecasts of size of the cluster varies from about $3 \times 10^{4} \mathrm{~km}^{2}$ for 30 -min forecast to $7 \times 10^{4} \mathrm{~km}^{2}$ for 120 -min forecast. The mean absolute error in prediction of size is above $31-38 \%$ of actual size for different lead periods of forecasts from 30 to $180 \mathrm{~min}$. There is over estimation in prediction of size for 30 and $60 \mathrm{~min}$ forecasts $(17 \%$ and $2.6 \%$ of actual size of the cluster, respectively) and underestimation in 90 to 180 -min forecasts $(-2.4 \%$ to $-28 \%$ ). The direct position error (DPE) based on the location of minimum CTBT ranges from 70 to $144 \mathrm{~km}$ for 30-180-min forecast respectively.

Keywords. Thunderstorm; MCS; CTBT; INSAT-3D; nowcast.

\section{Introduction}

Thunderstorm activity is one of the most severe weather hazard affecting India and neighbourhood, mainly during the months March-June (Srinivasan et al. 1973; Tyagi 2007). Meteorologists monitor the atmosphere for signs of severe thunderstorms development. They issue a severe thunderstorm warning for areas where conditions are favourable for the formation of severe storms as per standard operation procedure (India Meteorological Department (IMD) 2012). The horizontal size of a thunderstorm varies between a few kilometres and a few hundred kilometres and its time-scale 
from a few minutes to a few hours (Asnani 1993). The thunderstorm activity is greatly governed by the overall synoptic scale disturbances (Srinivasan et al. 1973).

The low level moisture and instability, and environmental conditions like horizontal and vertical wind shear, lower level vorticity, upper level divergence, triggering synoptic condition like trough, cyclonic circulation, low pressure systems, upper level trough/ridges etc. lead to thunderstorm activity (Srinivasan et al. 1973; Asnani 1993; IMD 2012). The field forecaster using the forecast based on synoptic charts as a guideline delineates the areas of a watch for development of thunderstorms. One has to depend heavily on reports of actual development of cumulonimbus clouds, thunderstorms, line squall etc. and their movement, observed by current weather stations or radar for purposes of operational warnings (such as thunderstorm warning for airfield and nowcast for a city). In this regard satellite imagery is also used to help track the movement of weather systems that might generate thunderstorms. Large scale thunderstorms usually occur in association with mesoscale convective systems (MCS) as observed through satellite. During March-June, MCS cover areal extent of $1000-10,000 \mathrm{~km}^{2}$ with life span of 1-3 hrs on many occasions (Tyagi et al. 2012; Goyal et al. 2014).

The monitoring and prediction of the MCS is attempted worldwide on nowcasting basis. The RADAR based nowcasting application software, 36 Warning Decision Support System Integrated Information (WDSS-II) developed by National Severe Storms Laboratory (USA) in collaboration with Oklahoma University (WDSS-II; Lakshmanan et al. 2007) is used in IMD for real-time. The WDSS-II provides a platform to play with weather data from multiple Radars and multiple sensors for detection of thunderstorms. The WDSSII has been installed in IMD at eight stations (Sen Roy et al. 2014). Due to limited stations, the coverage area is less. Another mesoscale model, Advance Regional Prediction System (ARPS) has also been attempted by IMD (Srivastava et al. 2010). These MCS are not forecasted well because of the absence of mesoscale observational network over Indian region and suitable expert system to cover the entire country. As there is inadequate radar network, satellite plays the dominant role for nowcast of these thunderstorms. In this study, a nowcast based algorithm ForTracc developed by Vila et al. (2008) is validated to predict
MCS over Indian region using Infrared Channel $(10.8 \mu \mathrm{m})$ of INSAT-3D. In this technique, the current location and intensity in terms of Cloud Top Brightness Temperature (CTBT) of the MCS are extrapolated. The purpose of this study is to validate this satellite based nowcasting technique for convective cloud clusters that helps in optimum utilization of satellite data and improves the nowcasting.

The observational and synoptic features of the severe thunderstorm/convective activities over Indian region and the characteristics of the satellite based nowcasting technique used for nowcasting of thunderstorms and convective cells is presented and discussed in section 2 . The performance of the nowcast technique for the prediction of the severe thunderstorm/convective activities are analyzed and presented in section 3. The broad conclusion of this study is presented in section 4 .

\section{Data and methodology}

A satellite based nowcast technique viz. Forecast and Tracking of Active Cloud Clusters (ForTraCC) developed by Vila et al. (2008) has been tested by Goyal et al. (2016) based on case study of intense thunderstorm activity over Bihar on 21 April, 2015. To have more robust assessment, 11 representative cases of convective activity over Indian region during the months (March-June) 2014 and 2015 (Ray et al. 2014, 2015). The details of 11 cases are given in table 1 . The cases which caused intense thunderstorm activity along with rainfall/hailstorm have been considered (figure 1). The cases represent different thunderstorm prone regions of India like southern peninsula, east and northeast India. The above data collected from Ray et al. $(2014,2015)$ and the weekly weather reports published by National Weather Forecasting Centre, IMD, New Delhi have been considered in this study. For the validation of the nowcast technique, half hourly satellite images of channel Thermal Infrared (TIR) $(10.8-11.5 \mu \mathrm{m})$ of INSAT-3D with spatial resolution of $4 \times 4 \mathrm{~km}^{2}$ has been considered to create nowcast up to next 180 min (every half hourly, table 2). The flowchart of this technique implemented in IMD is shown in figure 2.

The algorithm (Vila et al. 2008) for nowcasting of severe weather based on satellite imageries has been implemented in the IMD (Goyal et al. 2016). The algorithm is based upon the extrapolation technique that allows for the tracking of 


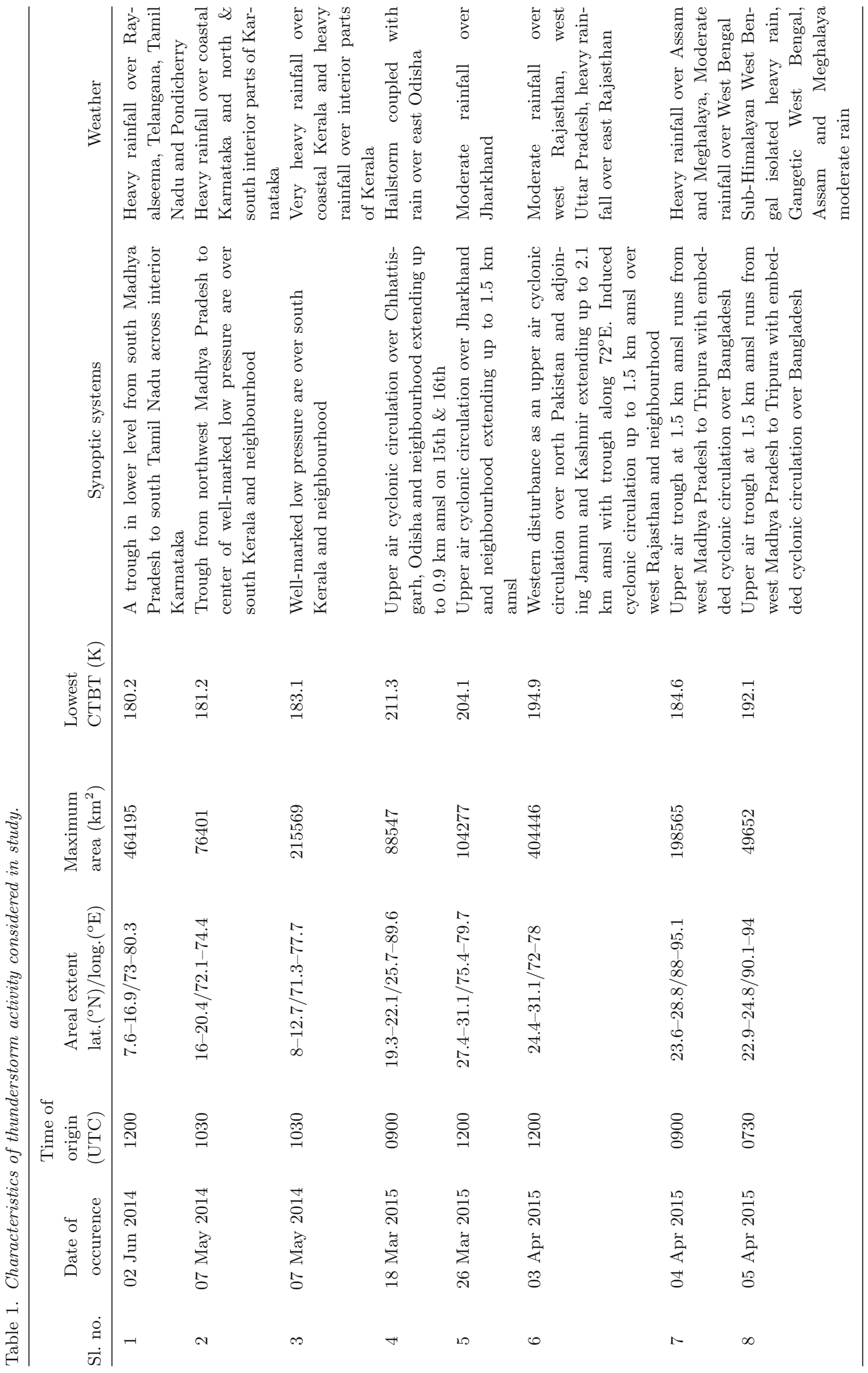


MCS radiative and morphological properties (Vila and Machado 2004). Using the infrared satellite data, based on CTBT, the algorithm is capable of forecasting evolution of the above said physical properties up to $360 \mathrm{~min}$. The studies by Goyal et al. (2016) have shown that the accuracy of the nowcast product is very less beyond $180 \mathrm{~min}$ and hence nowcast is issued for $180 \mathrm{~min}$ by IMD at present.

The features of the algorithm are discussed below:

(i) Following Maddox (1980) and Machado and Laurent (2004), an MCS with size $\geq 2400 \mathrm{~km}^{2}$ and temperature threshold $\leq 235 \mathrm{~K}\left(-38^{\circ} \mathrm{C}\right)$ is detected.

(ii) Successive images of MCS were applied on the statistical module to identify morphological and radiative parameters of each MCS. Tracking technique is applied on MCS overlapping areas between successive images according to Machado et al. (1998), Vila and Machado (2004).

(iii) MCS evolution in previous time steps were incorporated into a forecast model (Vila et al. 2008).

By considering the following three parameters, the forecast process is carried out. These parameters are:

- MCS displacement estimation.

- MCS area evolution based on the linear regression.

- MCS minimum brightness temperature temporal rate, also based on the linear regression.

A statistical method is used to estimate the brightness temperature of the MCS. It is hypothesized that the size evolution is linearly followed by a cloud-top variation with time $(\Delta T=\delta T \mathrm{~min} / \delta t)$, where $T$ is cloud top brightness temperature and $T$ min is minimum cloud top brightness temperature. A linear relationship is performed between normalised area of expansion, $\Delta E$ and $\Delta T$, which is also applied to the forecast procedure in order to obtain the evolution of the minimum temperature. The criteria for tracking the MCS, i.e., (i) area of cloud cluster $\geq 2400 \mathrm{~km}^{2}$ and (ii) $\mathrm{CTBT} \leq-38^{\circ} \mathrm{C}$ has been applied for tracking of cloud clusters for every half an hour (Goyal et al. 2016). The results were analysed for the half hourly forecasts available from the model in the actual scenario based on INSAT-3D observations. Since the forecast imageries contain the CTBT of cloud cluster, 


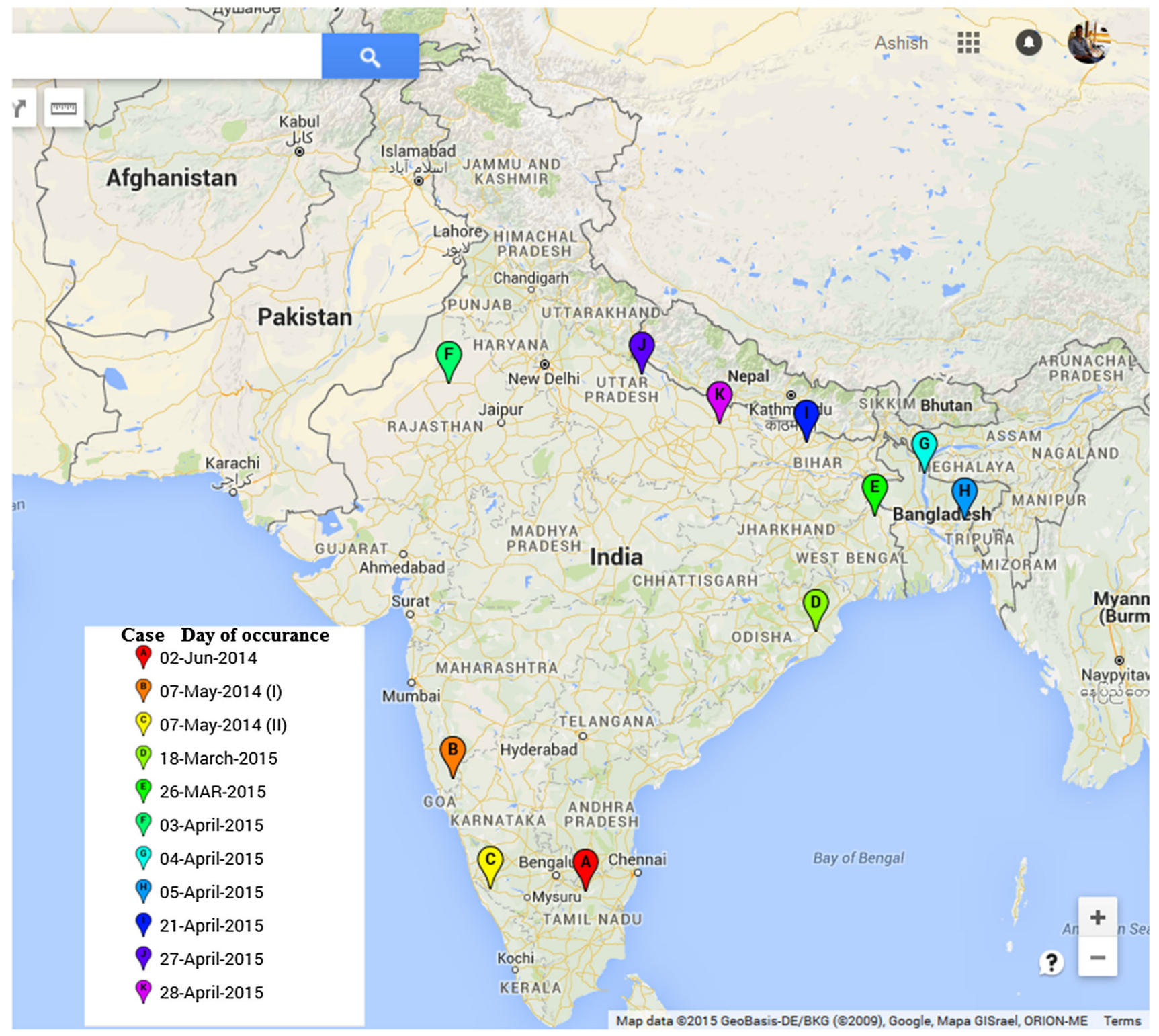

Figure 1. Cases of thunderstorm activity under study and their area of occurrence.

performance of the technique was calculated by comparing the predicted minimum CTBT, location of minimum CTBT, location of the mid-point of the cloud clusters and area of the cloud clusters with the actual. The results are presented and discussed in section 3 .

\section{Results and discussion}

\subsection{Comparison of predicted and actual CTBT}

Since we are taking brightness temperature as principal parameter for the nowcasting, so the comparison of the minimum CTBT of forecast convective cell with that of actual convective cell is carried out by plotting the scattered diagram and by calculating average absolute error (AAE) and root mean square error (RMSE) in minimum CTBT.

Figure 3 shows the scatter diagram of the observed and forecast minimum CTBT. Good agreement between the observed and forecasted values is observed for 30 and 60 min lead periods. The correlation coefficient (CC) between forecast and actual minimum CTBT is 0.8 up to $180 \mathrm{~min}$. Gradual decrease in forecast skill is observed with increase in time.

Figure 4(a) shows the AAE of minimum CTBT for every $30,60,90,120,150$ and $180 \mathrm{~min}$. It is found that the model could predict reasonably the minimum CTBT of the convective cell with AAE of $<7 \mathrm{~K}$ for different lead period. The AAE for 30 , $60,90,120,150$ and $180 \mathrm{~min}$ are 3.6, 4.8, 5.6, 6.0, 
Table 2. Number of forecast verified for the cases of thunderstorms considered in the study.

\begin{tabular}{|c|c|c|c|c|c|c|c|c|c|}
\hline \multirow[b]{2}{*}{ Sl. no. } & \multirow{2}{*}{$\begin{array}{l}\text { Date of } \\
\text { the event }\end{array}$} & \multirow{2}{*}{$\begin{array}{l}\text { Area of origin } \\
\text { convective cell }\end{array}$} & \multicolumn{7}{|c|}{ Number of forecasts issued with different lead periods (min) } \\
\hline & & & 30 & 60 & 90 & 120 & 150 & 180 & Total \\
\hline 1 & 02 Jun 2014 & Tamil Nadu and south AP & 3 & 3 & 3 & 3 & 3 & 3 & 18 \\
\hline 2 & 07 May 2014 & SW Maharashtra & 3 & 3 & 3 & 2 & 1 & 0 & 12 \\
\hline 3 & 07 May 2014 & $\begin{array}{l}\text { North Kerla adjoining } \\
\text { Karnatka }\end{array}$ & 3 & 3 & 3 & 2 & 1 & 0 & 12 \\
\hline 4 & 18 Mar 2015 & Odisha & 3 & 3 & 3 & 3 & 3 & 3 & 18 \\
\hline 5 & 26 Mar 2015 & West Bengal & 2 & 2 & 2 & 2 & 2 & 2 & 12 \\
\hline 6 & 03 Apr 2015 & Rajasthan & 3 & 3 & 3 & 3 & 2 & 1 & 15 \\
\hline 7 & 04 Apr 2015 & $\begin{array}{l}\text { Bangladesh adjoining SHWB } \\
\text { and Assam }\end{array}$ & 4 & 4 & 4 & 4 & 4 & 4 & 24 \\
\hline 8 & 05 Apr 2015 & Bangladesh & 3 & 3 & 3 & 3 & 3 & 3 & 18 \\
\hline 9 & 21 Apr 2015 & North Bihar adjoining Nepal & 5 & 5 & 4 & 3 & 2 & 1 & 20 \\
\hline 10 & 27 Apr 2015 & NW UP adjoining Nepal & 2 & 2 & 2 & 2 & 2 & 2 & 12 \\
\hline 11 & 28 Apr 2015 & East UP adjoining Nepal & 4 & 4 & 4 & 4 & 4 & 3 & 23 \\
\hline Total & & & 35 & 35 & 34 & 31 & 27 & 22 & 184 \\
\hline
\end{tabular}

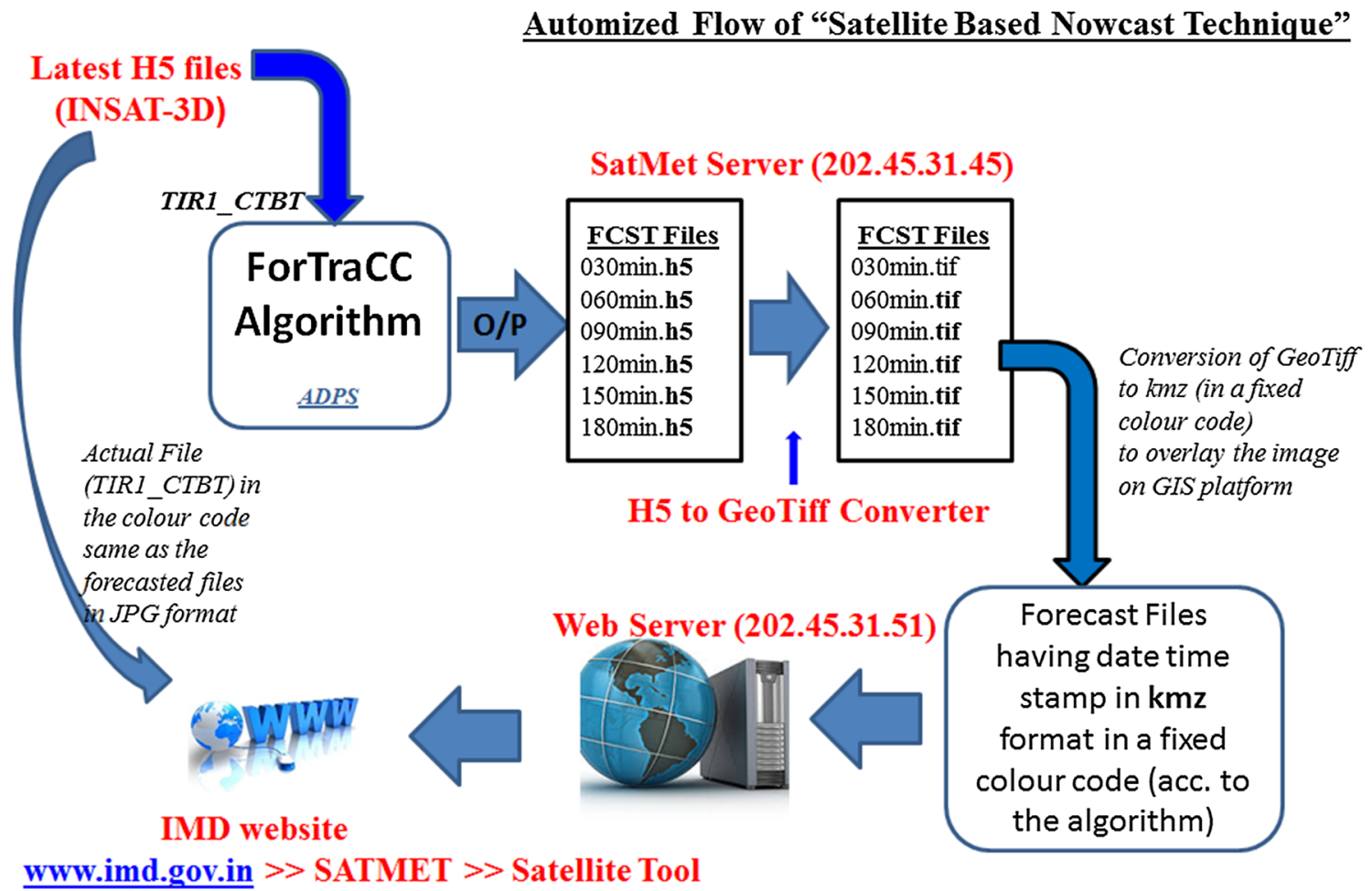

Figure 2. Automized flow chart of satellite-based nowcast technique in IMD.

6.3 and $6.6 \mathrm{~K}$, respectively. As shown in figure 4(a), the error gradually increases with increase in lead period of forecast. Similarly, the RMSE of minimum CTBT (figure 4b) for 30, 60, 90, 120, 150 and $180 \mathrm{~min}$ are $4.4,6.0,6.9,7.1,7.8$, and $8.3 \mathrm{~K}$, respectively.

From table 3 , it can be found that there is a negative bias in the forecast of minimum CTBT. Otherwise, the minimum CTBT is underestimated for all the lead periods of forecast from $30 \mathrm{~min}$ to $180 \mathrm{~min}$. It endorses the earlier findings of Vila et al. (2008). However, the negative bias is less than $1 \%$ of the actual minimum CTBT up to 120 min forecast and increases thereafter with increase in lead period. Considering the absolute mean difference in forecast and actual minimum CTBT, it varies from $1.9 \%$ of actual CTBT for $30 \mathrm{~min}$ forecasts to $2.91 \%$ for 120 min forecasts. 

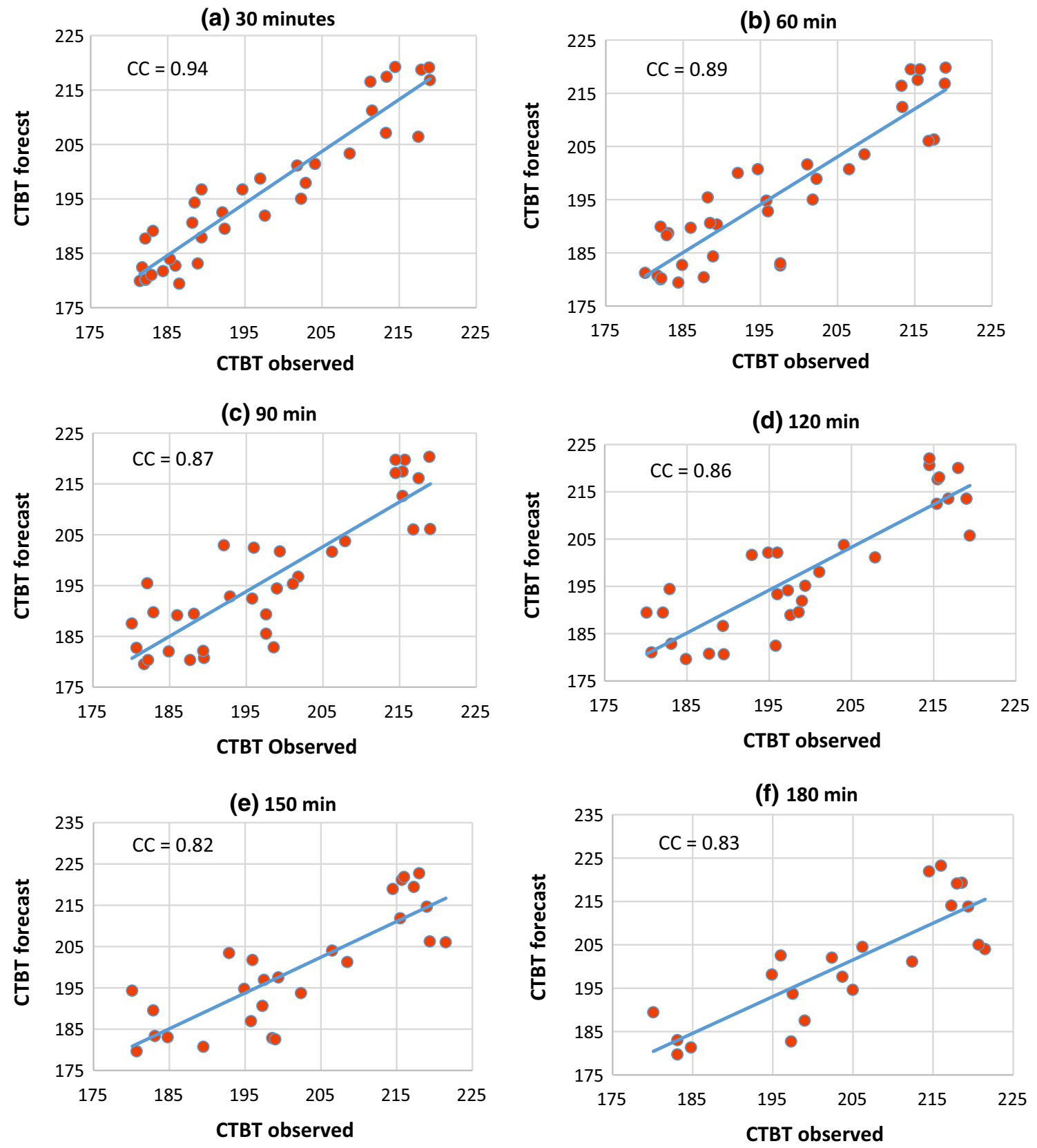

Figure 3. The observed and forecast CTBT of MCS during the validation period for (a) $30 \mathrm{~min}$, (b) $60 \mathrm{~min}$, (c) $90 \mathrm{~min}$, (d) $120 \mathrm{~min}$, (e) $150 \mathrm{~min}$, and (f) $180 \mathrm{~min}$ forecast. CC: Correlation coefficient. CCs significant at $95 \%$ level of confidence are highlighted.

ARPS model is developed by University of Oklahoma, USA and is validated for Indian region by Srivastava et al. (2010). By assimilating the radar data of DWR, the model provides forecast for $6 \mathrm{hrs}$ in the interval of $1 \mathrm{hr}$. According to the studies by Srivastava et al. (2010), the model underestimates the intensity by about $5 \mathrm{dBz}$.

WDSSII is an expert system used for operational nowcasting over Indian region. It utilizes DWR data to provide forecast up to $2 \mathrm{hrs}$. Sen Roy et al. (2014) have demonstrated that the error in nowcasting by this system is mostly in respect of location as well as the intensity of the cells. The overall error is minimum in the monsoon season and maximum during April-June.

\subsection{Comparison of predicted and actual area of cloud cluster}

The area of cluster is defined as the area covered by the cluster with CTBT of $235 \mathrm{~K}$ or less; the cluster with area of $>2400 \mathrm{~km}^{2}$ has been considered for the study. A good agreement is observed 
(a) AAE of forecast of minimum CTBT of Cloud

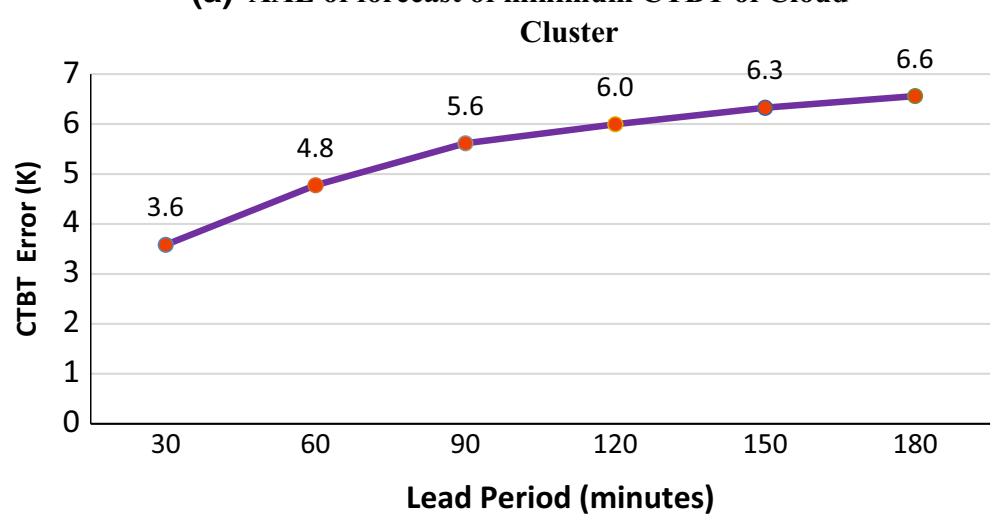

(b) RMSE of minimum CTBT

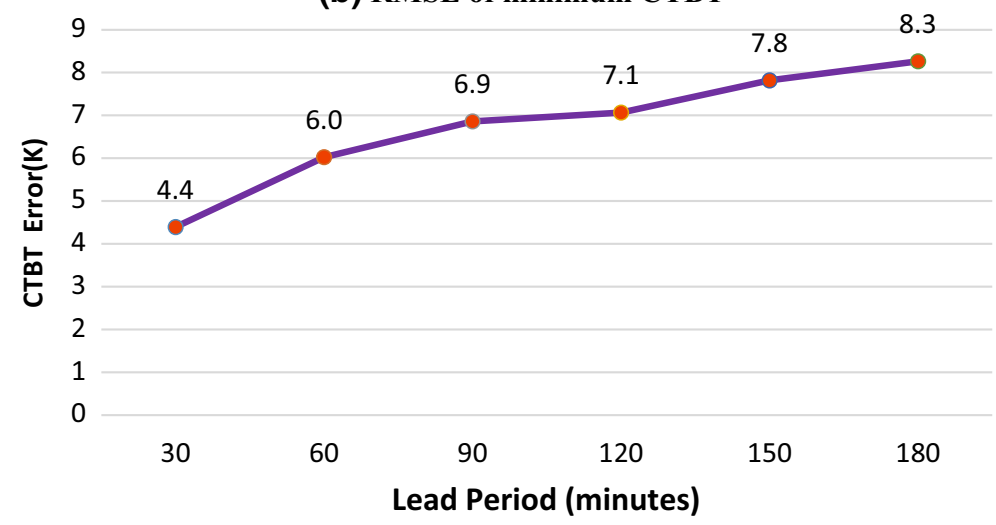

Figure 4. (a) Average Absolute Error (AAE) and (b) Root Mean Square Error (RMSE) in the prediction of minimum CTBT for the lead period of 30-180 min.

Table 3. Mean bias $(\Delta)$ and absolute bias of the size (expressed in \% to show the relative variations in size) and minimum temperature. Each row represents different lead periods (minutes).

\begin{tabular}{lcccr}
\hline $\begin{array}{l}\text { Lead period } \\
(\min )\end{array}$ & $\begin{array}{c}\text { Mean } \\
\Delta \mathrm{T}_{\min }(\%) \mathrm{K}\end{array}$ & $\begin{array}{c}\text { Absolute mean } \\
\Delta \mathrm{T}_{\min }(\%) \mathrm{K}\end{array}$ & $\begin{array}{c}\text { Mean } \Delta \text { size } \\
(\%) \mathrm{km}^{2}\end{array}$ & $\begin{array}{c}\text { Absolute mean } \\
\Delta \text { size }(\%) \mathrm{km}^{2}\end{array}$ \\
\hline 30 & -0.29 & 1.86 & 16.69 & 31.99 \\
60 & -0.55 & 2.42 & 2.56 & 35.00 \\
90 & -0.75 & 3.03 & -2.39 & 35.10 \\
120 & -0.56 & 2.91 & -12.69 & 38.14 \\
150 & -1.0 & 3.25 & -27.95 & 36.58 \\
180 & -1.57 & 3.19 & & \\
\hline
\end{tabular}

$\Delta \operatorname{Tmin}=\frac{\text { Forecast Tmin }- \text { Actual Tmin }}{\text { Actual Tmin }} \times 100, \quad \Delta$ size $=\frac{\text { Forecast size-Actual size }}{\text { Actual size }} \times 100$.

between actual and forecasted area of cloud clusters as shown in scatter diagram (figure 5). The correlation coefficient of $>0.9$ is observed up to $180 \mathrm{~min}$. The correlation decreases with increase in lead period.

The AAE and RMSE in the forecast of size of the cluster are calculated and presented in figure 6. It clearly shows that the error increases with increase in lead period. The AAE varies from about $3 \times 10^{4} \mathrm{~km}^{2}$ for 30 min forecast to $7 \times 10^{4} \mathrm{~km}^{2}$ for 120 min forecast in terms of AAE. It varies from $4 \times 10^{4}$ to $11 \times 10^{4} \mathrm{~km}^{2}$ in terms of RMSE. From table 3 , there is positive bias or overestimation in prediction of size for 30 and $60 \mathrm{~min}$ forecasts, i.e., $17 \%$ and $2.6 \%$ of actual size of the cluster respectively. There is negative bias or underestimation in 90 to $180 \mathrm{~min}$ forecasts, i.e., $-2.4 \%$ to $-28 \%$ respectively. The mean absolute error in prediction of size is above $31-38 \%$ of actual size for different lead periods of forecasts from 30 to $180 \mathrm{~min}$. 
(a) $30 \mathrm{~min}$

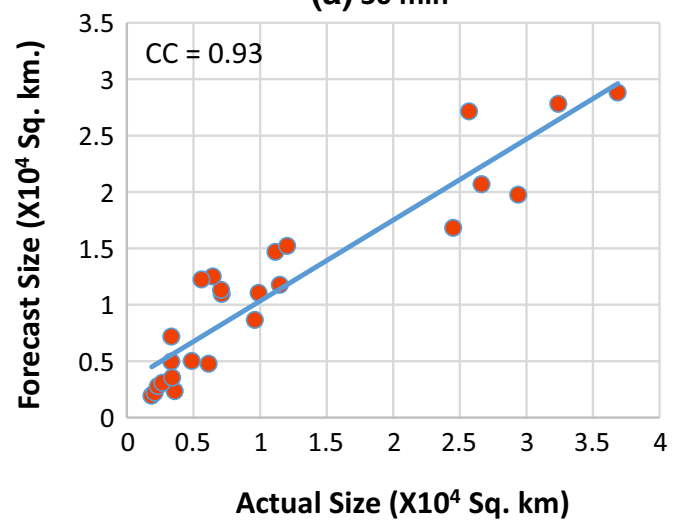

(c) $90 \mathrm{~min}$

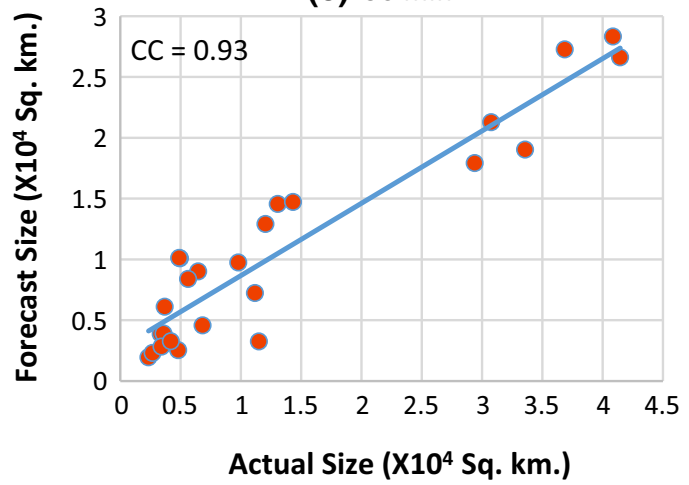

(e) $150 \mathrm{~min}$

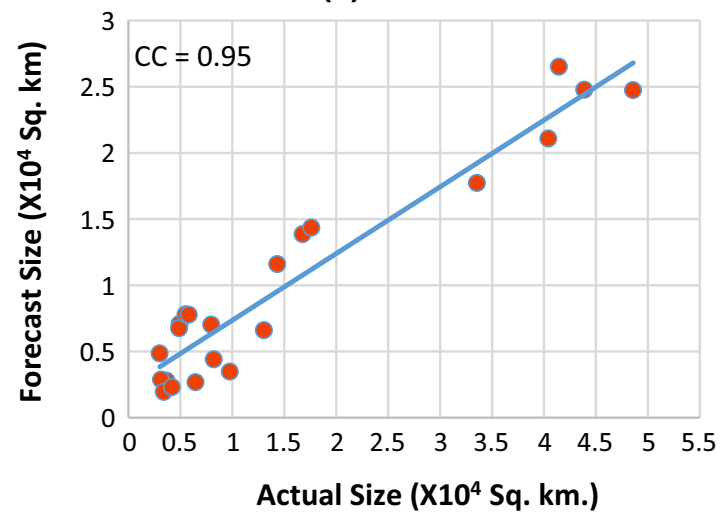

(b) $60 \mathrm{~min}$

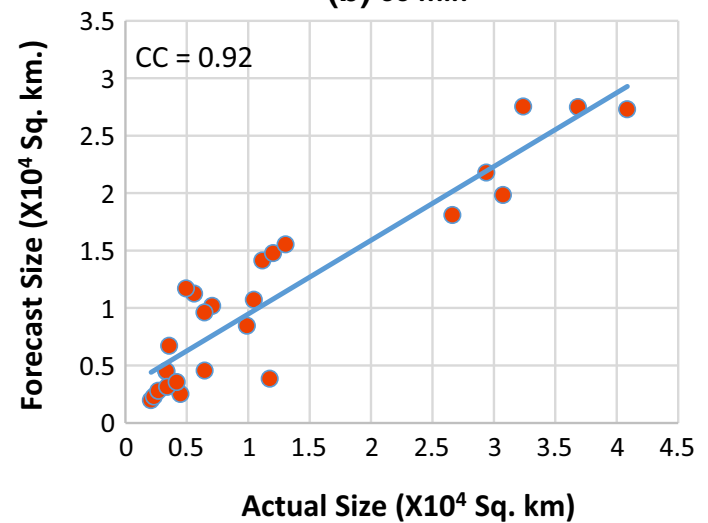

(d) $120 \mathrm{~min}$

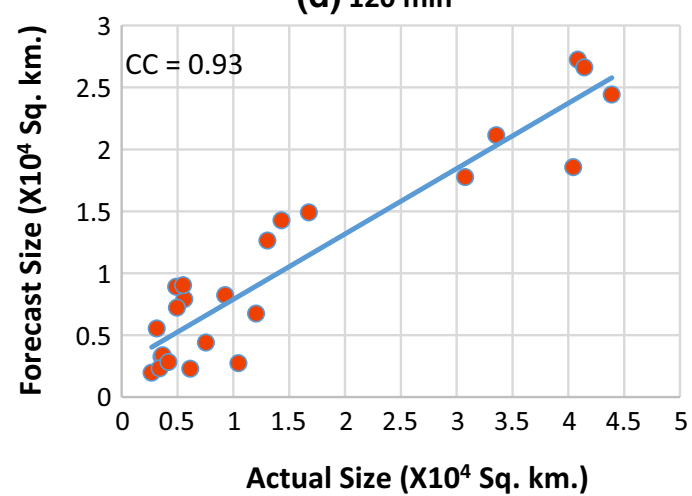

(f) $180 \mathrm{~min}$

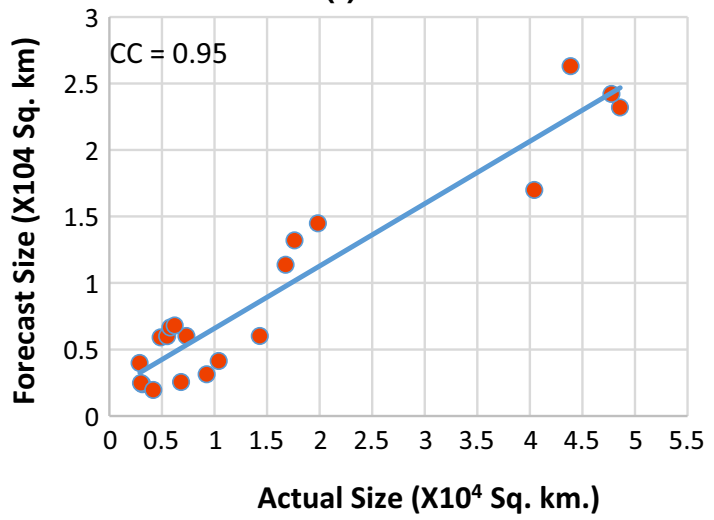

Figure 5. The observed and forecast size of MCS during the validation for (a) $30 \mathrm{~min}$, (b) $60 \mathrm{~min}$, (c) $90 \mathrm{~min}$, (d) $120 \mathrm{~min}$, (e) $150 \mathrm{~min}$, and (f) $180 \mathrm{~min}$ forecast. CC: Correlation coefficient. CCs significant at $95 \%$ level of confidence are highlighted.

Comparing the AAE as percentage of actual value of minimum CTBT and size, the minimum CTBT is better predicted than the size of cluster (table 3). It also endorses the earlier findings of Vila et al. (2008). While the actual size decreases, the actual minimum CTBT increases. Otherwise, with the decrease in size, the intensity of the cluster also decreases. Considering the forecast parameters, when the forecast size decreases the forecast minimum CTBT increases or the intensity of the cluster decreases.

\subsection{MCS size and temperature evolution}

The evolution of the forecast parameters like forecast minimum CTBT and forecast size of the MCS has been compared to actual minimum CTBT and size of the MCS for individual cases. The objective is to find out whether there is any relationship between the size and intensity of the cluster.

Figure 7 shows the size and minimum temperature evolution for a single MCS present at 0100 UTC of 27 March 2015. Solid lines represent the 

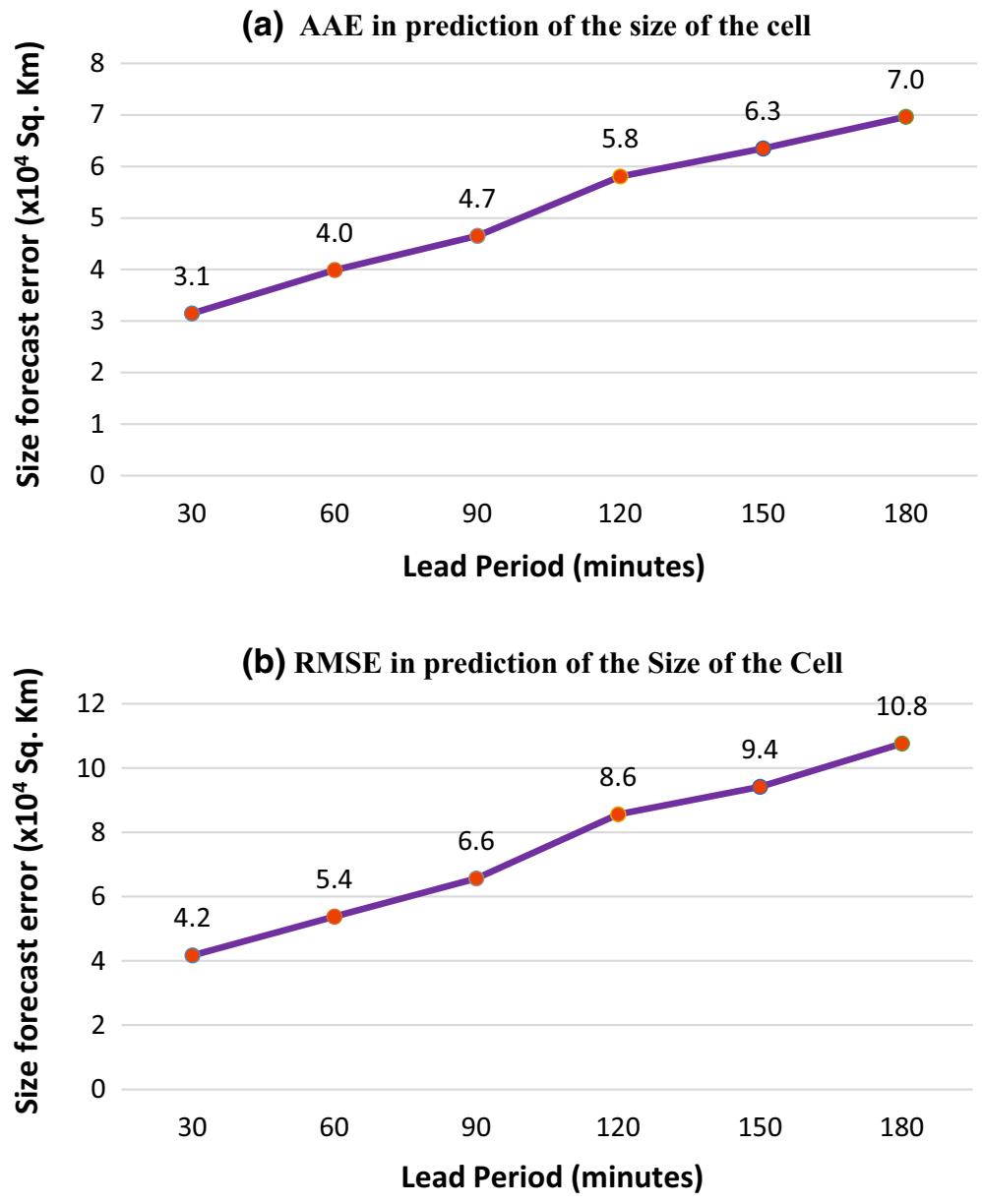

Figure 6. (a) Average Absolute Error (AAE) and (b) Root Mean Square Error (RMSE) in the prediction of size of cloud cluster for the lead period of 30-180 $\mathrm{min}$.

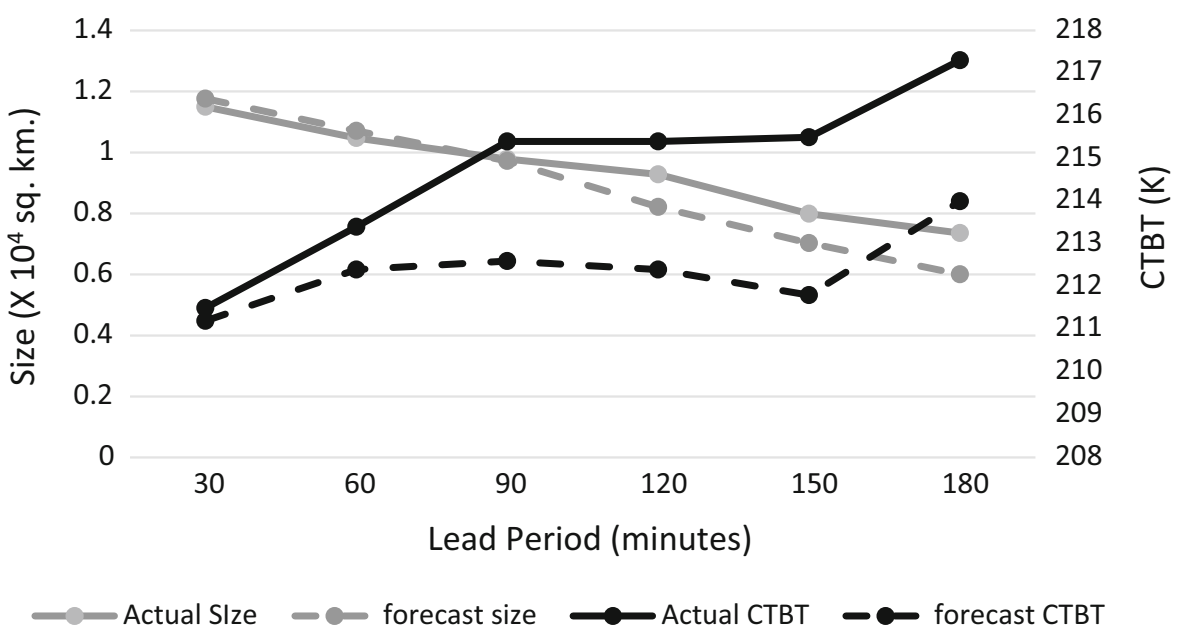

Figure 7. Size and minimum temperature evolution for single MCS of 27th March 2015 at 0100 UTC.

observed values for both parameters, while dotted lines represent the forecast obtained with satellite based nowcast tool for different time leads. The minimum CTBT is underestimated in the forecast. The forecast size of the MCS almost agrees with the actual upto $90 \mathrm{~min}$ and then it is underestimated. Similar findings have also been demonstrated by Vila et al. (2008) for the MCS over Atlantic region for the same nowcast model. 
(a) Average direct position error based on Location of minimum CTBT

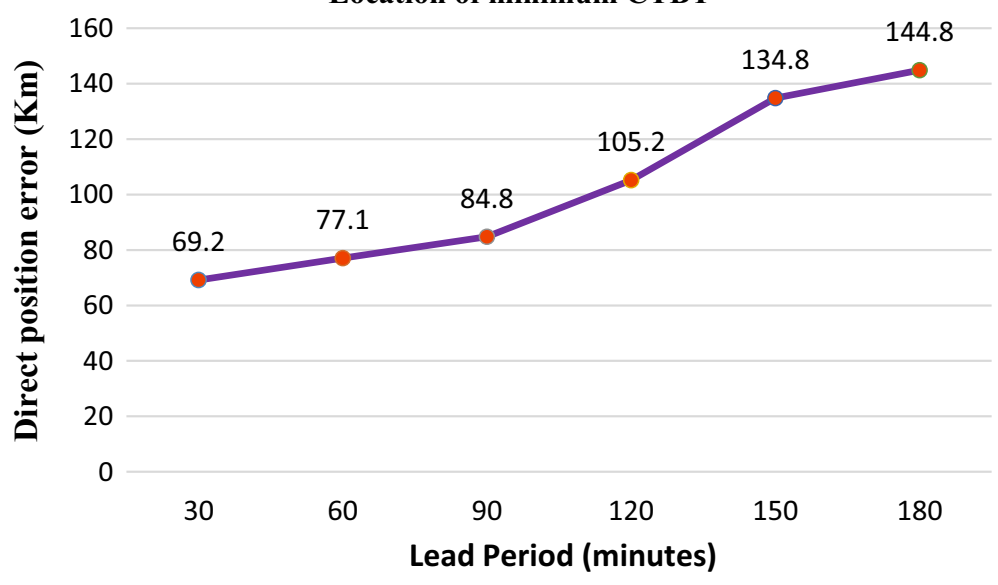

(b) Average direct position error based on Center of

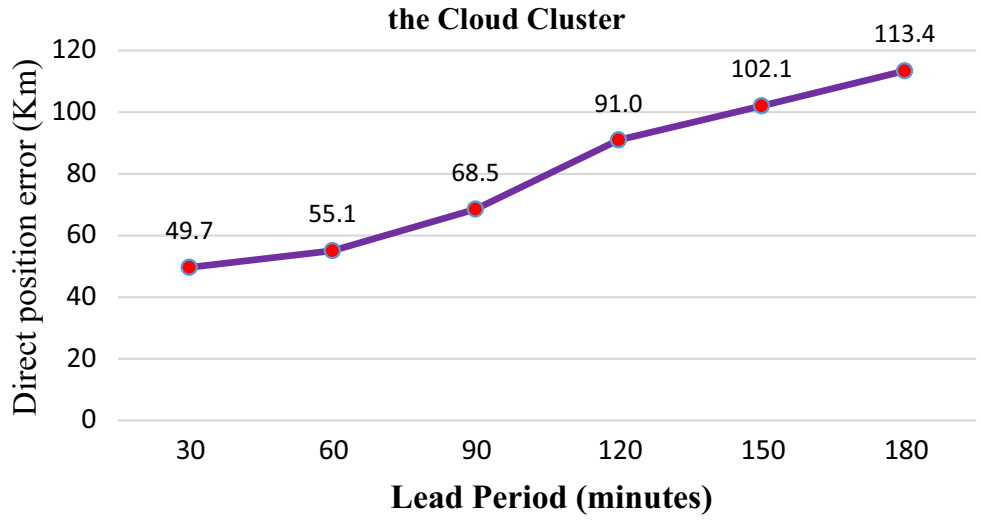

Figure 8. Average direct position error based on (a) location of minimum CTBT and (b) location of center of cloud cluster for the lead period of $30-180$ min.

Table 4. Mean latitudinal and longitudinal errors in the prediction of track of convective cluster based on minimum CTBT.

\begin{tabular}{lccccc}
\hline & \multicolumn{2}{c}{ Latitude error } & & \multicolumn{2}{c}{ Longitude error } \\
\cline { 2 - 3 } \cline { 5 - 5 } $\begin{array}{l}\text { Lead period } \\
\text { min })\end{array}$ & $\begin{array}{c}\text { Mean error } \\
(\mathrm{km})\end{array}$ & $\begin{array}{c}\text { Absolute mean error } \\
(\mathrm{km})\end{array}$ & & $\begin{array}{c}\text { Mean error } \\
(\mathrm{km})\end{array}$ & $\begin{array}{c}\text { Absolute mean error } \\
(\mathrm{km})\end{array}$ \\
\hline 30 & -3.3 & 41.8 & & 8.8 & 42.9 \\
60 & 0.5 & 39.6 & & -5.5 & 56.1 \\
90 & 6.6 & 52.3 & -18.7 & 60.5 \\
120 & 6.6 & 46.2 & -35.2 & 79.2 \\
150 & 1.1 & 42.9 & -41.8 & 118.8 \\
180 & 11.0 & -28.6 & 134.2
\end{tabular}

$\overline{\text { Latitude } \text { error }=\text { forecast latitude-actual latitude. Longitude error }=\text { forecast longitude-actual }}$ longitude.

\subsection{Track forecast error}

The track forecast error has been calculated in two different ways. It is defined as Direct Position Error (DPE) between the actual position of minimum CTBT and the forecast position of the minimum CTBT. In a second approach, it is defined as the DPE between the center of actual and forecast MCS. The error is calculated for every half hourly forecast. The average DPE on the basis of location of minimum CTBT are shown in figure 8(a). It clearly shows that the error is increasing with the increase in lead period. The error ranges from 70 to $144 \mathrm{~km}$ for $30-180 \mathrm{~min}$ forecast. It is $<100 \mathrm{~km}$ up to $90 \mathrm{~min}$ forecasts. 
Table 5. Mean latitudinal and longitudinal errors in the prediction of track of convective cluster based on centroid.

\begin{tabular}{lccccc}
\hline & \multicolumn{2}{c}{ Latitude error } & & \multicolumn{2}{c}{ Longitude error } \\
\cline { 2 - 3 } \cline { 5 - 6 } $\begin{array}{l}\text { Lead period } \\
(\mathrm{min})\end{array}$ & $\begin{array}{c}\text { Actual error } \\
(\mathrm{km})\end{array}$ & $\begin{array}{c}\text { Absolute error } \\
(\mathrm{km})\end{array}$ & & $\begin{array}{c}\text { Actual error } \\
(\mathrm{km})\end{array}$ & $\begin{array}{c}\text { Absolute error } \\
(\mathrm{km})\end{array}$ \\
\hline 30 & 5.5 & 23.1 & & 14.3 & 34.1 \\
60 & 2.2 & 23.1 & & 11.0 & 42.9 \\
90 & -8.8 & 19.8 & & -4.4 & 62.7 \\
120 & -9.9 & 37.4 & & -14.3 & 83.6 \\
150 & -14.3 & 53.9 & & -27.5 & 98.4 \\
180 & -8.8 & 48.4 & & -14.3 & 90.2
\end{tabular}

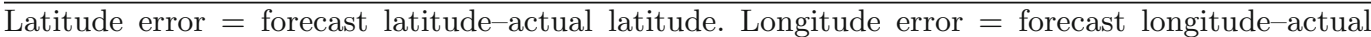
longitude.

The average DPE based on location of center of cloud cluster is shown in figure 8(b). It shows less error than the DPE calculated for the location of minimum CTBT. The DPE ranges from 49 to $113 \mathrm{~km}$. The error is less than $100 \mathrm{~km}$ up to 120 min forecasts. It may be due to fact that due to vertical wind shear and interaction with midlatitude westerlies, the distribution of CTBT may be asymmetric and hence away from geographical center.

The mean latitudinal and longitudinal error in prediction of track of MCS are presented in tables 4 and 5 based on location of minimum CTBT and location of centroid of MCS, respectively. It is found that the latitude error based on minimum CTBT varies from $41.8 \mathrm{~km}$ for $30 \mathrm{~min}$ to $52.8 \mathrm{~km}$ for $60 \mathrm{~min}$ forecast. The longitude error varies from $42.9 \mathrm{~km}$ for $30 \mathrm{~min}$ forecast to $79.2 \mathrm{~km}$ for 120 min forecast. It is significantly higher for $180 \mathrm{~min}$. The latitude error based on centroid (table 5) varies from 23.1 to $37.4 \mathrm{~km}$ for $30-120 \mathrm{~min}$ forecast and longitudinal error varies from 34.1 to $90.2 \mathrm{~km}$ for 30-120 min forecast. Hence there is longitudinal bias in the forecast track of the MCS.

\section{Conclusions}

The satellite based nowcast technique developed by Vila et al. (2008) has been installed and tested based on 11 representative cases of convective activity over Indian region during March-June.

The model could predict reasonably the minimum CTBT of the convective cell with AAE of $<7 \mathrm{~K}$ for different lead periods. The AAE for 30, 60, 90, 120, 150 and $180 \mathrm{~min}$ are 3.6, 4.8, 5.6, 6.0, 6.3 and $6.6 \mathrm{~K}$, receptively. The RMSE of minimum CTBT for 30, 60, 90, 120,150 $180 \mathrm{~min}$ are $4.4,6.0,6.9,7.1,7.8$, and $8.3 \mathrm{~K}$, respectively. There is a negative bias is the forecast of minimum CTBT, i.e., the minimum CTBT is underestimated for all the lead periods of forecasts from 30-180 min.

The error in the forecast of size of the cluster varies from about $3 \times 10^{4} \mathrm{~km}^{2}$ for 30 min forecasts to $7 \times 10^{4} \mathrm{~km}^{2}$ for $120 \mathrm{~min}$ forecast in terms of $\mathrm{AAE}$ and from $4 \times 10^{4}$ to $11 \times 10^{4} \mathrm{~km}^{2}$ in terms of RMSE. The mean absolute error in prediction of size is above $31-38 \%$ of actual size for different lead periods of forecasts from 30 to 180 min. There is positive bias or over estimation in prediction of size for 30 and $60 \mathrm{~min}$ forecasts, i.e., $17 \%$ and $2.6 \%$ of actual size of the cluster respectively and there as negative bias or underestimation in 90-180 min forecasts, i.e., $-2.4 \%$ to $-28 \%$ respectively.

The DPE based on the location of minimum CTBT ranges from 70 to $144 \mathrm{~km}$ for $30-180 \mathrm{~min}$ respectively. It is $<100 \mathrm{~km}$ up to $90 \mathrm{~min}$ forecasts. There is a longitudinal bias in the prediction of track of the MCS.

\section{Acknowledgements}

The authors extend their thanks to Space Application Centre (ISRO), Ahmedabad for providing necessary help for installation and operationalization of the software. The authors also thank Dr Denial Vila for providing his nowcasting technique (ForTraCC) and sharing the information with us.

\section{References}

Asnani G C 1993 Tropical Meteorology (Sindh Colony, Aundh, Pune 411007, India 1993), II, 1202. 
Goyal S, Kumar A, Sangar G and Mohapatra M 2016 Severe thunderstorm activity over Bihar on 21st April, 2015: A simulation study by satellite based nowcasting technique; Proc. SPIE 98\%6, Remote Sensing of the Atmosphere, Clouds, and Precipitation VI, 987612.

Goyal S, Sikka D R and Tyagi A 2014 Morphology of long lasting meso-scale convective system under week synoptic forcing over the Gangetic plain in May 2010 during the STORM-2010 campaign; Mausam 65(3) $333-352$.

IMD 2012 Standard operation procedure: Weather forecasting and warning; India Meteorological Department, Lodi road, Delhi.

Lakshmanan V, Smith T, Stumpf G and Hondl K 2007 The warning decision support system-integrated information (WDSS-II); Wea. Forecasting 22 592-608.

Machado L A T and Laurent H 2004 The convective system area expansion over Amazonia and its relationships with convective system life duration and high-level wind divergence; Mon. Wea. Rev. 132 714-725.

Machado L A T, Rossow W B, Guedes R L and Walker A W 1998 Life cycle variations of mesoscale convective systems over the Americas; Mon. Wea. Rev. 126 1630-1654.

Maddox R A 1980 Mesoscale convective complex; Bull. Am. Meteor. Soc. 61 1374-1387.

Ray K, Bandopadhyay B K, Sen B, Sharma P, Warsi A, Mohapatra M, Yadav B P, Debnath G C, Stella S, Das S, Duraisamy M, Rajeev V K, Barapatre V, Paul S, Singh H, Das A K, Bhan S C, Sikka D R, Tyagi A, Das S and Rathore L S 2014 Thunderstorms 2014 - A Report.

Ray K, Bandopadhyay B K, Sen B, Sharma P, Warsi A H, Mohapatra M, Yadav B P, Debnath G C, Stella S, Das S, Duraisamy M, Rajeev V K, Barapatre V, Paul S, Shukla
P, Madan R, Goyal S, Das A K, Bhan S C, Chakravarthy K and Rathore L S 2015 Pre-Monsoon Thunderstorms 2015: A Report (SAARC STORM PROJECT-2015), India Meteorological Department, Nowcasting Unit, Scientific Report No.: ESSO/IMD/SMRC STORM Project2015/01/(2015)/4.

Sen Roy S, Saha B, Roy Bhowmik S K and Kundu P K 2014 Optimization of nowcast software WDSS-II for operational application over the Indian region; Meteor. Atmos. Phys. 124(3-4) 143-166.

Srivastava K, Roy Bhowmik S K, Sen Roy S, Thampi S B and Reddy Y K 2010 Simulation of high impact convective events over Indian region by ARPS model with assimilation of Doppler weather radar radial velocity and reflectivity; Atmofera 23(1) 53-73.

Srinivasan V, Ramamurthy K and Nene Y R 1973 India Meteorological department forecasting manual. PartIII: Discussion of Typical Synoptic Weather Situations; Deputy Director General of Meteorology (Forecasting) Poona, FMU Report No. III-2.2, December 1973.

Tyagi A 2007 Thunderstorm climatology over Indian region; Mausam 58 189-212

Tyagi A, Sikka D R, Goyal S and Bhowmick M 2012 A satellite based study of pre-monsoon thunderstorm (Nor'westers) over eastern India and their organization into mesoscale convective complexes; Mausam 63(1) $29-54$.

Vila D A and Machado L A T 2004 Shape and radiative properties of convective systems observed from infrared satellite images; Int. J. Remote Sens. 25 4441-4456.

Vila D A, Machado L A T, Laurent H and Velasco I 2008 Forecast and Tracking the Evolution of Cloud Clusters (ForTraCC) using satellite infrared imagery: Methodology and validation; Wea. Forecasting 23 233-245. 